\title{
Soil Respiratory Quotient Determined via Barometric Process Separation Combined with Nitrogen-15 Labeling
}

\author{
Christoph Müller,* M. Kaleem Abbasi, Claudia Kammann, Tim J. Clough, Robert R. Sherlock, \\ R. James Stevens, and Hans-Jürgen Jäger
}

\begin{abstract}
The barometric process separation (BaPS) and ${ }^{15} \mathrm{~N}$ dilution techniques were used to determine gross nitrification rates on the same soil cores from an old grassland soil. The BaPS-technique separates the $\mathrm{O}_{2}$ consumption into that from nitrification and that from soil organic matter (SOM) respiration. The most sensitive parameter for the calculations via the BaPS technique is the respiratory quotient $\left(\mathrm{RQ}=\Delta \mathrm{CO}_{2} / \Delta \mathrm{O}_{2}\right)$ for SOM turnover $\left(\mathrm{RQ}_{\text {som }}\right)$. Combining both methods (BaPS- ${ }^{15} \mathrm{~N}$ ) allowed the determination of the $R Q_{\text {som. }}$. The RQ value determined in such a way is adjusted for the influence of nitrification and denitrification, which are both characterized by totally different $R Q$ values. The results for the grassland soil showed that 6 to $10 \%$ of $\mathrm{O}_{2}$ was consumed by nitrification when incubated at $20^{\circ} \mathrm{C}$ and $0.49 \mathrm{~g} \mathrm{H}_{2} \mathrm{O} \mathrm{g}{ }^{-1}$ soil. A set of BaPS measurements with the same soil at various temperature and moisture contents showed that up to $49 \%$ of the total $\mathrm{O}_{2}$ consumption was due to nitrification. The calculated $\mathbf{R Q}_{\text {sом }}$ values via the BaPS- ${ }^{15} \mathbf{N}$ technique presented here are more closely associated with the overall SOM turnover than the usual net $\mathbf{R Q}$ reported in the literature. Furthermore, the $\mathbf{R} \mathbf{Q}_{\text {son }}$ value provides an overall indication of the decomposability and chemical characteristics of the respired organic material. Hence, it has the potential to serve as a single state index for SOM quality and therefore be a useful index for SOM turnover models based on substrate quality.
\end{abstract}

$T$ HE RQ in soil is defined as the ratio of mole $\mathrm{O}_{2}$ uptake per mole $\mathrm{CO}_{2}$ respired $\left(\Delta \mathrm{CO}_{2} / \Delta \mathrm{O}_{2}\right)$. In aerobic soils the measured $\mathrm{RQ}$ value is usually in the range of 0.6 to 1.0 (Andersen and Scagel, 1997; Klein, 1977). The RQ value is frequently higher than 1.0 (Dilly, 2001) under anaerobic conditions, when alternative electron acceptors are available (e.g., $\mathrm{NO}_{3}^{-}$) or shortly after substrate (e.g., glucose) addition stimulating microbial growth. In general, the $\mathrm{RQ}$ decreases as the $\mathrm{C} / \mathrm{O}$ ratio in the components being metabolized increases (e.g., mineralization of humic acids has a RQ of 0.909; Dilly, 2001). A RQ value of 1.0 is obtained only under conditions when the respired $C$ substrate has a chemical composition comparable with that of glucose (Dilly, 2001). Therefore, the RQ value of metabolized SOM in soils provides an indication of the substrate utilization. The observed temporal variations in $\mathrm{RQ}$ values under field conditions are associated with variations in substrate

C. Müller, M.K. Abbasi, C. Kammann, and H.-J. Jäger, Dep. of Plant Ecology, Univ. of Giessen, Heinrich-Buff-Ring 26-32, 35392 Giessen, Germany; T.J. Clough and R.R. Sherlock, Soil, Plant and Ecological Sciences Division, Soil and Physical Sciences Group, P.O. Box 84, Lincoln Univ., Canterbury, New Zealand; R.J. Stevens, Agriculture, Food and Environmental Science Division, The Dep. of Agriculture and Rural Development, Newforge Lane, Belfast BT9 5PX, Northern Ireland, UK. Received 10 Nov. 2003. *Corresponding author (Christoph. Mueller@bot2.bio.uni-giessen.de).

Published in Soil Sci. Soc. Am. J. 68:1610-1615 (2004).

(c) Soil Science Society of America

677 S. Segoe Rd., Madison, WI 53711 USA utilization patterns (Dilly, 2001), the microbial community structure (e.g., proportions of bacteria to fungi) (Klein, 1977) and abiotic factors such as soil moisturetemperature relationships (Klein, 1977; Scagel and Andersen, 1997).

In all previous studies the net $R Q\left(R Q_{\text {net }}\right)$ is measured rather than the exact $\mathrm{RQ}$ resulting from $\mathrm{SOM}$ turnover $\left(\mathrm{RQ}_{\text {Som }}\right)$ alone. The $\mathrm{RQ}_{\text {net }}$ integrates the effects of all microbial transformations that consume $\mathrm{O}_{2}$ and consume or produce $\mathrm{CO}_{2}$. For instance, denitrification utilizing $\mathrm{NO}_{3}^{-}$instead of $\mathrm{O}_{2}$ increases the overall $\mathrm{RQ}_{\text {net }}$ when occurring in anaerobic microsites within the surrounding aerobic soil. Autotrophic nitrification, however, decreases the $\mathrm{RQ}_{\text {net }}$ because it takes up $\mathrm{O}_{2}$ and $\mathrm{CO}_{2}$ according to a ratio of 1.68 moles of $\mathrm{O}_{2}$ to 0.23 moles of $\mathrm{CO}_{2}$ (Ingwersen et al., 1999). In particular the effect of nitrification in lowering the RQ value might be considerable but in most cases it is not taken into account (Dilly, 2001).

To investigate the relationship between nitrification and $\mathrm{RQ}$ values, both the gross nitrification rates as well as the $\mathrm{O}_{2}$ and $\mathrm{CO}_{2}$ dynamics have to be determined. The BaPS technique for determination of gross nitrification rates combines all of these requirements and is therefore ideally suited for such an analysis (Ingwersen et al., 1999; UMS, 2003). The BaPS technique requires specifications of soil and microbial parameters that are readily available (e.g., $\mathrm{pH}$, soil moisture) but also more specific parameters that are usually not known such as: (a) the ratio of $\mathrm{N}_{2} \mathrm{O} / \mathrm{N}_{2}$ during denitrification, (b) the ratio of autotrophic/heterotrophic nitrification, and (c) the RQ during soil respiration (default RQ value used in the calculations is 1.0). Sensitivity analyses showed that $\mathrm{Pa}$ rameters $a$ and $b$ have only a minor influence, but small changes in the RQ value have a large effect on the calculated gross nitrification rates (Breuer et al., 2002; Ingwersen et al., 1999). Therefore, a cross-comparison of the BaPS results with an independent method for gross nitrification rate determination is needed. In addition, such a cross-comparison would provide a basis for accurate setting of the Parameters $a$ through $c$ needed for the BaPS calculations. The most widely used method to determine gross nitrification rates in soil is the ${ }^{15} \mathrm{~N}$ dilution technique (Stark, 2000). Furthermore, specific ${ }^{15} \mathrm{~N}$ labeling techniques exist to derive ratios of autotrophic/heterotrophic nitrification (Müller et al., 2004) and ratios of $\mathrm{N}_{2} \mathrm{O} / \mathrm{N}_{2}$ (Stevens and Laughlin, 1998) in soil.

\footnotetext{
Abbreviations: aut/(aut + het), ratio of autotrophic to total nitrification; BaPS, barometric process separation; $\mathrm{BaPS}-{ }^{15} \mathrm{~N}$, combined barometric process separation $-{ }^{15} \mathrm{~N}$ labeling technique; RN-ratio, total mole $\mathrm{CO}_{2}$ produced per mole of $\mathrm{N}$ nitrified; $\mathrm{RQ}$, respiratory quotient; $\mathrm{RQ}_{\text {net }}$, total mole $\mathrm{O}_{2}$ uptake per mole $\mathrm{CO}_{2}$ respired $\left(\Delta \mathrm{CO}_{2} / \Delta \mathrm{O}_{2}\right) ; \mathrm{RQ}_{\text {som, }}, \mathrm{RQ}$ related to SOM turnover; SOM, soil organic matter.
} 
The aim of this study was to determine the effect of nitrification on RQs following fertilizer application and to derive RQ values related to SOM turnover in soil.

\section{MATERIALS AND METHODS}

\section{Experimental Setup}

Undisturbed soil cores (on average $224 \mathrm{~g}$ dry soil per core) were taken from the top $50 \mathrm{~mm}$ of an old grassland soil (organic C 6.6\%; pH 6.2) near Giessen, Germany. The soil is classified as a Fluvic Gleysol with a texture of sandy clay loam over a clay layer. The site and soil, as well as the experiment where BaPS field measurements have been performed (see below), are described in more detail by Jäger et al. (2003). Eighteen soil samples were collected in $250-\mathrm{mL}$ stainless steel rings (height of $50 \mathrm{~mm}$, diameter of $80 \mathrm{~mm}$ ) on 8 Apr. 2003 and incubated (field moisture, $20^{\circ} \mathrm{C}$ ) for $5 \mathrm{~d}$. The cores were sealed in parafilm with pinholes for gas exchange to minimize water loss but allow aeration. Nitrogen was applied to each soil core on 14 Apr. 2003 at a rate of $40 \mu \mathrm{g} \mathrm{N} \mathrm{g}^{-1}$ of dry soil in a total of $10.5 \mathrm{~mL}$ divided among the three soil depths per core using a seven-needle applicator to assure an even distribution of the applied $\mathrm{N}$. The application increased the $\mathrm{NH}_{4}^{+}$and $\mathrm{NO}_{3}^{-}$concentrations from typical background concentrations of 1.0 and $0.6 \mu \mathrm{g} \mathrm{N} \mathrm{g}^{-1}$ dry soil to 13.9 and $23.2 \mu \mathrm{g} \mathrm{N} \mathrm{g}^{-1}$ dry weight, respectively. The $\mathrm{N}$ source was $\mathrm{NH}_{4} \mathrm{NO}_{3}$ with a 60 atom $\%{ }^{15} \mathrm{~N}$ excess enrichment on the $\mathrm{NO}_{3}^{-}$. The soil moisture over the entire measurement period was on average $0.49 \pm$ $0.04 \mathrm{~g} \mathrm{H}_{2} \mathrm{O} \mathrm{g}^{-1}$ dry soil.

\section{Analytical Procedures}

Measurements with the BaPS- and the ${ }^{15} \mathrm{~N}$-technique were performed at 1.4, 22.5, and $69.9 \mathrm{~h}$ after $\mathrm{N}$ application. At each measuring time, three $250-\mathrm{mL}$ cores were placed in the BaPS incubation vessel and incubated at $20^{\circ} \mathrm{C}$ for periods of up to $6 \mathrm{~h}$ (Ingwersen et al., 1999). At the end of each measuring period three $12-\mathrm{mL}$ gas samples were taken from the headspace of the BaPS unit and analyzed for $\mathrm{N}_{2} \mathrm{O}$ and $\mathrm{N}_{2}$ concentrations and their ${ }^{15} \mathrm{~N}$ enrichments (Stevens et al., 1993). At the same time as the BaPS measurements commenced, separate soil cores were extracted with $2 \mathrm{M} \mathrm{KCl}$ (each $200 \mathrm{~g}$ fresh soil) using the procedure described by Stevens and Laughlin (1995). The cores from the BaPS measurements were extracted in an identical manner immediately after the incubation. The $\mathrm{KCl}$ extracts were analyzed for concentrations of $\mathrm{NO}_{3}^{-}$after reduction to $\mathrm{NO}_{2}^{-}$in a Cd column by a manual photometric method (Schlichting et al., 1995). The $\mathrm{NO}_{3}^{-}$concentrations were corrected for the $\mathrm{NO}_{2}^{-}$concentrations. The ${ }^{15} \mathrm{~N}$ contents of the $\mathrm{NO}_{3}^{-}$in the extracts were determined by a method based on their conversion to $\mathrm{N}_{2} \mathrm{O}$ (Stevens and Laughlin, 1994). All gas samples were analyzed using automated continuous-flow isotope mass spectrometry (PDZ-Europa, Crewe, UK).

\section{Gross Nitrification Calculations}

The determination of the gross nitrification rate via the BaPS-technique was performed with the BaPS software (UMS, Version 1.9.8). The ratio of $\mathrm{N}_{2} \mathrm{O} / \mathrm{N}_{2}$ was set to 1.0 , which was close to the observed ratio of 1.4 at $22.5 \mathrm{~h}$ and 1.0 at $69.9 \mathrm{~h}$ (see below). The ratio of autotrophic to total nitrification [aut/(aut + het)] was set to 0.5 because this was close to the observed ratio in a separate experiment performed on the same soil (Müller et al., 2004). The RQ was left at the default value of 1.0. The gross nitrification rates were calculated via the "regression analysis" option. With this option it is possible to select the data within a user-defined range over which regressions are calculated and subsequently used in the calculations. The BaPS software determines a single rate integrated over the three cores enclosed in the BaPS unit. The error of the calculated mean nitrification rate is based on errors in the inputs (soil and headspace volume, soil weight, water content, $\mathrm{pH}$ ), uncertainties in the special parameters $\left(\mathrm{N}_{2} \mathrm{O} / \mathrm{N}_{2}\right.$, aut/( aut + het $\left.), \mathrm{RQ}\right)$ and sensor uncertainties $\left(\mathrm{O}_{2}\right.$, $\mathrm{CO}_{2}$, pressure, and temperature sensors) (UMS, 2003). Therefore, it is difficult to compare the error associated with the BaPS-derived rates with standard deviations (sd) calculated using data from actual repetitions. While the BaPS-technique calculates errors based on error propagation of all single possible error sources this is usually not done for replicated measurements.

The gross nitrification rates determined by the ${ }^{15} \mathrm{~N}$ dilution technique were calculated for the same time periods over which the BaPS measurements were performed. For this calculation the $\mathrm{NO}_{3}^{-}$concentrations and ${ }^{15} \mathrm{~N}$ enrichments obtained from the soil analysis at the beginning and just after each BaPS measurement were required (two-point method). The calculations were based on the model by Kirkham and Bartholomew (1954) that calculates nitrification and N immobilization rates according to zero-order kinetics. In the original Kirkham and Bartholomew model, immobilized mineral N does not enter the organic $\mathrm{N}$ pool, that is, the mineralizing $\mathrm{N}$ pool stays at natural abundance. We modified the model so that immobilized $\mathrm{N}$ enters the organic $\mathrm{N}$ pool and therefore allows for remineralization of immobilized $\mathrm{N}$. Two $\mathrm{N}$ pools, a natural abundance and a labeled $\mathrm{NO}_{3}^{-}$pool were considered. The natural abundance pool was not divided into an $\mathrm{NH}_{4}^{+}$and an organic $\mathrm{N}$ pool and therefore the calculated nitrification rate is the combined heterotrophic and autotrophic nitrification, that is, the same as the BaPS-output. The model was set up in the software ModelMaker (Family Genetix, Reading, UK) and the zero-order rate constants were optimized using the Marquardt-Levenberg algorithm with the "reasonable error" option based on observed standard deviations (Müller et al., 2004). The model outputs an average rate with a realistic error estimate. The optimization was performed separately for the three observation periods.

\section{Barometric Process Separation Measurements at Field Conditions}

Barometric process separation measurements were performed on several occasions during 2001-2003 within 3 to $5 \mathrm{~d}$ (per occasion) on a set of three cores from 0- to 5-cm depth taken from the control rings of the Giessen Free-Air Carbon dioxide Enrichment (FACE) Experiment (Jäger et al., 2003). The undisturbed cores were incubated in the BaPS unit for about 5 to $12 \mathrm{~h}$ under ambient field soil moisture and average field temperatures at the time of sampling. Barometric process separation measurements were performed in November 2001, March, May, July, and November 2002, and in May and July 2003 , under various soil moisture (range: $0.13-0.65 \mathrm{~g} \mathrm{H}_{2} \mathrm{O} \mathrm{g}^{-1}$ dry soil) and temperature conditions (range $8-23.5^{\circ} \mathrm{C}$ ). The RQ was set to 0.90 for the calculation of gross nitrification rates via BaPS (for further explanation see below Results and Discussion section Respiratory Quotient Values and Their Relationship to Nitrification Rates).

\section{Respiratory Quotient Determination}

Using the gross nitrification rates obtained from the ${ }^{15} \mathrm{~N}$ dilution technique as a guide for the BaPS measurements, it was possible to calculate the RQ for soil respiration by keeping all settings the same but adjusting the RQ and the ratio aut/ 
Table 1. Respiratory quotient values determined by the barometric process separation (BaPS) technique $\left(R Q_{\text {net }}\right)$ and by the combined BaPS $-{ }^{15} \mathbf{N}$ technique $\left(\mathrm{RQ}_{\text {som }}\right)$ at three times after $\mathbf{N}$ application to a grassland soil incubated at $20^{\circ} \mathrm{C}$.

\begin{tabular}{lccc}
\hline $\begin{array}{l}\text { Hours after } \\
\text { N application }\end{array}$ & $\mathbf{R Q}_{\text {net }}$ & $\mathbf{R Q}_{\text {soM }}$ & \% difference $\dagger$ \\
\hline $\mathbf{1 . 4}$ & $\mathbf{0 . 8 3}$ & $\mathbf{0 . 9 1}$ & $\mathbf{8 . 8}$ \\
$\mathbf{2 2 . 5}$ & $\mathbf{0 . 8 1}$ & $\mathbf{0 . 9 2}$ & $\mathbf{1 3 . 6}$ \\
$\mathbf{6 9 . 9}$ & $\mathbf{0 . 7 9}$ & $\mathbf{0 . 8 8}$ & $\mathbf{1 1 . 4}$ \\
\hline
\end{tabular}

$\dagger$ Calculated on the basis of the $R Q_{\text {net }}$ as $\left(\mathbf{R Q}_{\text {som }}-\mathbf{R} \mathbf{Q}_{\text {net }}\right) / \mathbf{R} \mathbf{Q}_{\text {net }} \times 100$.

(aut + het) in the "special parameter" options of the BaPS software. The ratio aut/(aut + het) was taken from a separate experiment performed with the same soil and set to 0.92 at $1.4 \mathrm{~h}, 0.853$ at $22.5 \mathrm{~h}$, and 0.762 at $69.9 \mathrm{~h}$ after $\mathrm{N}$ application (Müller et al., 2004). In the separate experiment autotrophic and heterotrophic nitrification were determined after the application of $\mathrm{NH}_{4} \mathrm{NO}_{3}$ where the $\mathrm{NH}_{4}^{+}$, the $\mathrm{NO}_{3}^{-}$or both moieties were labeled with ${ }^{15} \mathrm{~N}$. A ${ }^{15} \mathrm{~N}$-tracing model was developed and applied to the data set obtained from this grassland soil to quantify gross $\mathrm{N}$ transformation rates. The model was only successful when autotrophic and heterotrophic nitrification (i.e., $\mathrm{N}$ transformation from organic $\mathrm{N}$ to $\mathrm{NO}_{3}^{-}$) was considered (Müller et al., 2004).

The RQ parameter in the current study was adjusted for each observation so that the BaPS-calculated nitrification rates agreed with the rates obtained from the ${ }^{15} \mathrm{~N}$ technique. Slight discrepancies between the calculated gross nitrification rates via $\mathrm{BaPS}$ and the ${ }^{15} \mathrm{~N}$ method may occur because the BaPS software only allows the input of RQ value with a maximum of two decimal places. Furthermore, the BaPS software used for this analysis does not have the option to use gross nitrification rates as input parameters; therefore, the easiest way to determine RQ values was the use of the manual adjustment procedure.

The combination of both techniques is referred to as BaPS${ }^{15} \mathrm{~N}$ method. In addition, the $\mathrm{RQ}_{\text {net }}$ values were determined by using the uncorrected $\Delta \mathrm{CO}_{2} / \Delta \mathrm{O}_{2}$ mole fractions from the BaPS output (Table 1 ), that is, the values that would normally be used to calculate the RQ value.

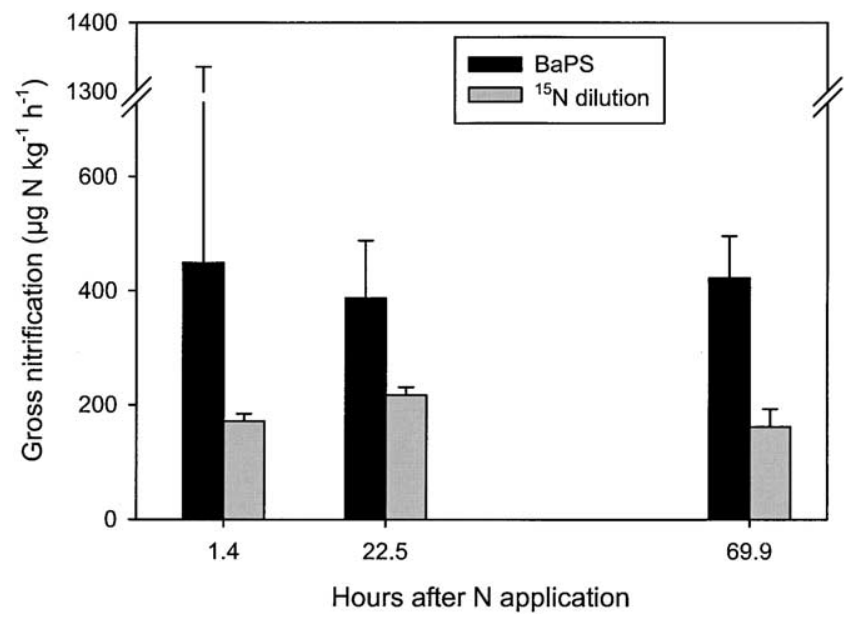

Fig. 1. Gross nitrification rates $\left[a v g \pm\right.$ standard deviation $\left({ }^{15} \mathbf{N}\right)$ or \pm error (BaPS)] determined by BaPS and the ${ }^{15} \mathbf{N}$ dilution techniques (using the default value for the respiratory quotient, $\mathbf{R} \mathbf{Q}_{\text {som }}$, of 1.0) for soil incubated at $20^{\circ} \mathrm{C}$ (the error calculated by BaPS is based on error propagation instead of standard deviation, see Materials and Methods above for further explanations).

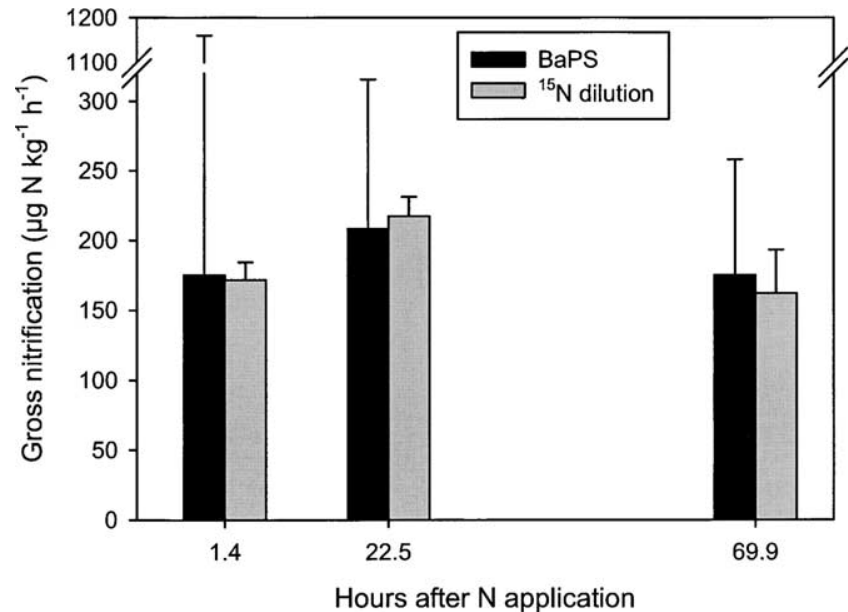

Fig. 2. Gross nitrification rates [avg \pm standard deviation $\left({ }^{15} \mathbf{N}\right)$ or \pm error (BaPS)] determined by the ${ }^{15} \mathrm{~N}$ dilution technique and by the BaPS technique after adjustment of aut/(aut + het) ratio with measured ratios and optimization of the respiratory quotient $\left(\mathrm{RQ}_{\text {som }}\right)$ for soil incubated at $20^{\circ} \mathrm{C}$.

\section{RESULTS AND DISCUSSION}

\section{Nitrification Rate and Respiratory Quotient Values for Soil at $20^{\circ} \mathrm{C}$}

Without adjustment of the RQ values, the BaPS method calculated gross nitrification rates ranging from 387 to $448 \mu \mathrm{g} \mathrm{N} \mathrm{kg}{ }^{-1} \mathrm{~h}^{-1}$. These rates were 1.5 to 2.5 times higher than those determined by the ${ }^{15} \mathrm{~N}$ dilution technique (Fig. 1). The nitrification rates determined using the ${ }^{15} \mathrm{~N}$ method $\left(160-220 \mu \mathrm{g} \mathrm{N} \mathrm{kg}{ }^{-1} \mathrm{~h}^{-1}\right)$ agreed well with nitrification rate of $202 \mu \mathrm{g} \mathrm{N} \mathrm{kg}{ }^{-1} \mathrm{~h}^{-1}$ observed in this soil after $\mathrm{N}$ application in a previous study (Müller et al., 2004) and observations from other comparable old grassland ecosystems (Stockdale et al., 2002; Watson and Mills, 1998). The errors associated with the two methods cannot be compared due to the different methods for calculating error (see Materials and Methods above).

Adjusting the aut/(aut + het) parameters for the BaPS calculations lowered the gross nitrification rates by only 4 to $6 \%$. Only through the adjustment of the RQ to 0.91 at $1.4 \mathrm{~h}, 0.92$ at $22.5 \mathrm{~h}$ and 0.88 at $69.9 \mathrm{~h}$ after $\mathrm{N}$ application was it possible to lower the BaPScalculated nitrification rates to the rates determined with the ${ }^{15} \mathrm{~N}$ technique (Fig. 2). The rates of $\mathrm{CO}_{2}$ respired and $\mathrm{O}_{2}$ consumed at the three measuring times are presented in Fig. 3. The results from the BaPS measurements show that 6 to $10 \%$ of the total $\mathrm{O}_{2}$ consumption in the grassland soil was related to nitrification activity (Fig. 3).

\section{Respiratory Quotient Values and Their Relationship to Nitrification Rates}

The RQ values calculated on the net molar change of $\mathrm{CO}_{2}$ and $\mathrm{O}_{2}$ (i.e., net $\Delta \mathrm{CO}_{2} / \Delta \mathrm{O}_{2}$ ) differed between 0.08 and 0.11 (i.e., up to $14 \%$ on the basis of $\mathrm{RQ}_{\text {net }}$ ) compared with the $\mathrm{RQ}_{\mathrm{som}}$ values determined with the BaPS $-{ }^{15} \mathrm{~N}$ method (Table 1). To assess the influence of $\mathrm{CO}_{2}$ production and nitrification on the differences 


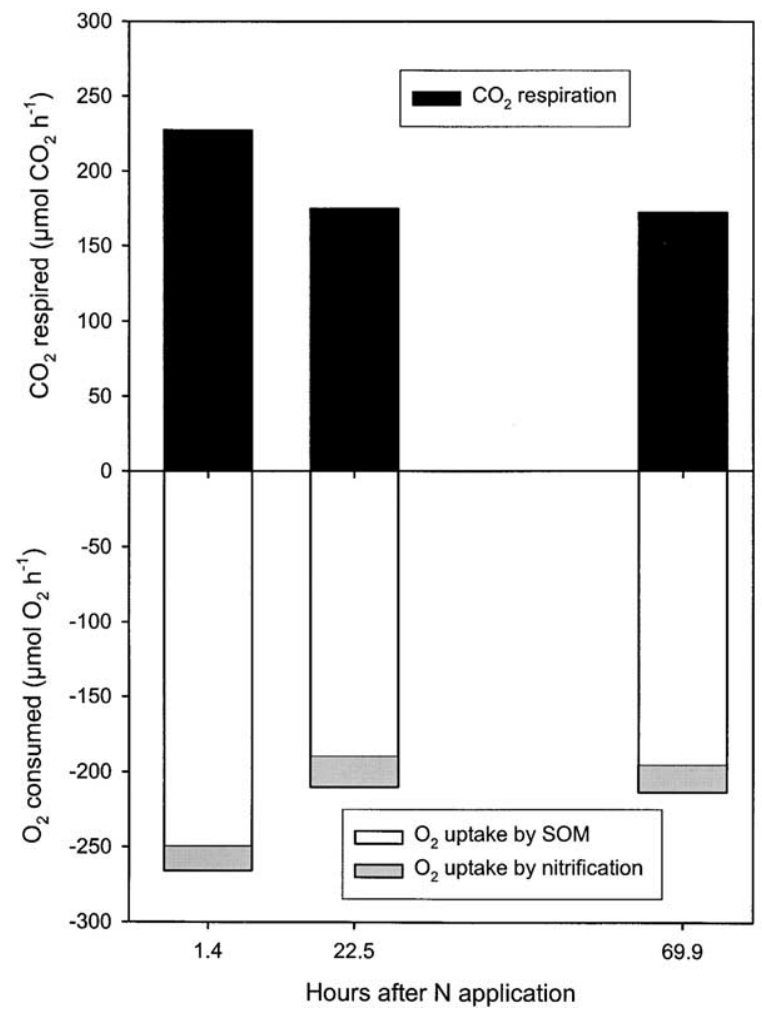

Fig. 3. Carbon dioxide respiration and $\mathrm{O}_{2}$ consumption by the SOM and nitrification at the three measurement times after $\mathrm{N}$ addition to soil incubated at $20^{\circ} \mathrm{C}$.

between $\mathrm{RQ}_{\text {som }}$ and $\mathrm{RQ}_{\text {net }}$, we used data from the same soil obtained over a period of more than $2 \mathrm{yr}$ where the BaPS technique had been used under various soil moisture and soil temperature conditions. Since all of the measurements at field conditions were performed during times when the mineral $\mathrm{N}$ concentrations were low or at typical background values, the $\mathrm{RQ}_{\text {som }}$ value determined toward the end our BaPS $-{ }^{15} \mathrm{~N}$ study at $20^{\circ} \mathrm{C}$ was used for the calculations (i.e., when mineral $\mathrm{N}$ concentrations had decreased toward the end of the incubation period the $\mathrm{RQ}_{\text {Sом }}$ approached a value of 0.90 ). The relative difference between $R Q_{\text {som }}$ and $R_{Q_{\text {net }}}$ values, as presented in Table 1 for soil at $20^{\circ} \mathrm{C}$, was calculated for soil at field conditions and related to the ratio of moles $\mathrm{CO}_{2}$ produced per moles of $\mathrm{N}$ nitrified, (the $\mathrm{RN}$-ratio; Fig. 4). For field conditions, RQ differences up to $37 \%$ were observed which were associated with an $\mathrm{O}_{2}$ consumption by nitrification of $49 \%$ of the total $\mathrm{O}_{2}$ uptake (i.e., calculated as $\mu \mathrm{mol} \mathrm{O}_{2}$ consumption during nitrification in percentage of total $\mu$ mole of $\mathrm{O}_{2}$ consumption; Fig. 4). The best fit for the data in Fig. 4 was a firstorder model ( $r^{2}=0.97$; Eq. [1]).

$$
\mathrm{RQ}_{\text {diff }}=\mathrm{RQ}_{\text {diff min }}+a \exp (-b \mathrm{RN})
$$

where

$$
\mathrm{RQ}_{\text {diff }}=\frac{\mathrm{RQ}_{\mathrm{sOM}}-\mathrm{RQ}_{\text {net }}}{\mathrm{RQ}_{\text {net }}}
$$

$\mathrm{RQ}_{\text {diff min }}=$ minimum RQ-difference $\left(\mathrm{mol} \mathrm{CO}_{2} \mathrm{~mol}^{-1} \mathrm{O}_{2}\right)$ $\{0.0593601\} ; \mathrm{RN}=$ mole $\mathrm{CO}_{2}$ produced per mole of $\mathrm{N}$

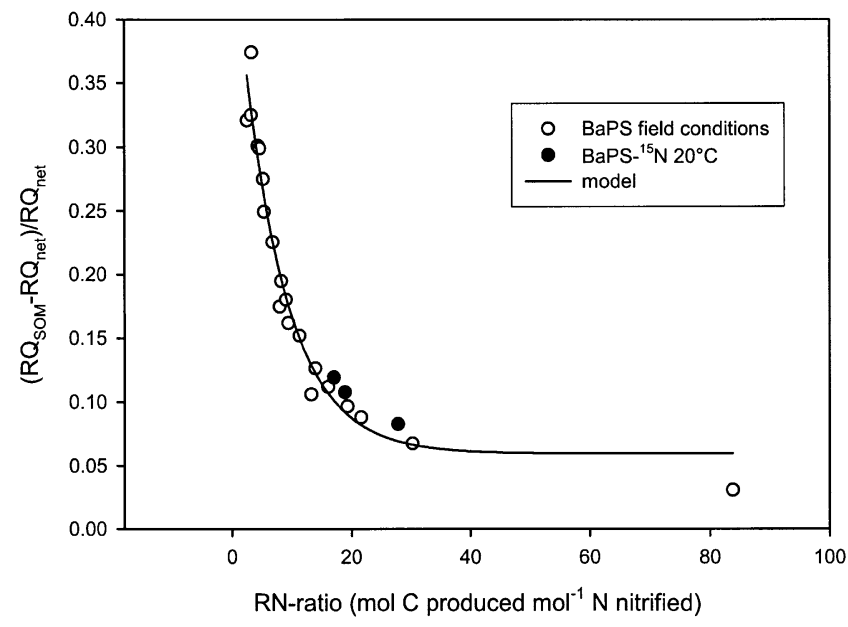

Fig. 4. Relationship between the difference of $\mathbf{R Q} \mathbf{Q}_{\text {som }}-\mathbf{R Q} \mathbf{Q}_{\text {net }} \mathbf{e x}$ pressed as a fraction of $\mathrm{RQ}_{\text {net }}$ and the ratio of total soil $\mathrm{CO}_{2}$ production to gross nitrification from BaPS measurements performed on the same grassland soil at field conditions between 2001-2003.

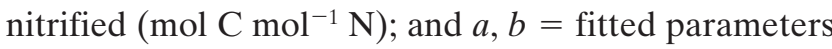
$\{0.416891 ; 0.135053$.

The model (Eq. [1]) indicated exponentially increasing relative differences with decreasing $\mathrm{RN}$-ratios, that is, the error in assuming that $\mathrm{RQ}_{\mathrm{SOM}}$ is represented by the $\mathrm{RQ}_{\text {net }}$ value rises exponentially when the gross nitrification increases and the $\mathrm{CO}_{2}$ production decreases. Rearranging Eq. [1] would allow for the determination of the $R Q_{\text {som }}$ value if the $R N$ ratio and the $R Q_{\text {net }}$ values were known.

The theoretical effect of varying gross nitrification rates on $\mathrm{RQ}_{\text {SoM }}$ in the 0 to $600 \mu \mathrm{g} \mathrm{N} \mathrm{kg}{ }^{-1} \mathrm{~h}^{-1}$ range was simulated for the three observation periods when soil was incubated at $20^{\circ} \mathrm{C}$. The calculated values depended on the nitrification rate and varied between 0.8 and 1.15 (Fig. 5). Furthermore, the relationships between nitrification rate and $\mathrm{RQ}_{\text {Som }}$ were different at different times after $\mathrm{N}$ application. In particular, the relationship

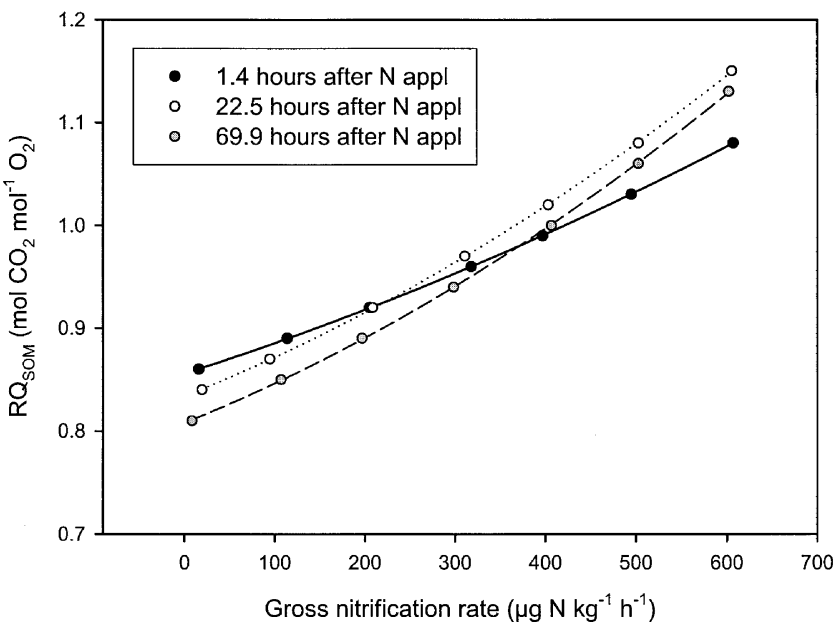

Fig. 5. The influence of gross nitrification rates on the calculated respiratory quotient $\left(\mathbf{R Q}_{\text {som }}\right)$ of the barometric process separation calculations at 1.4, 22.5, and $69.9 \mathrm{~h}$ after $\mathrm{N}$ application to soil incubated at $20^{\circ} \mathrm{C}$ (regression lines are in the form of a quadratic equation: $\mathbf{y}=\mathbf{a}+\mathbf{b} \boldsymbol{x}+\mathbf{c} \boldsymbol{x}^{2}$ ). 
shortly after $\mathrm{N}$ application (1.4 h) appeared to be different from the relationships at 22.5 and 69.9 h (Fig. 5).

The importance of the RQ value on the exact calculation of gross nitrification using the BaPS technique has recently been shown by Breuer et al. (2002) working on intact cores from tropical rainforest soil in Australia. They used an iterative procedure to determine the RQ value. However, this procedure could only be used for a RQ range of 0.95 to 1.05 because outside this range the error in the nitrification rate was too large (Breuer et al., 2002). Here we show that RQ values in the old grassland soil were always below 0.95 and therefore unsuitable for such an iterative procedure. The slight increase in the RQ value $1 \mathrm{~d}$ after $\mathrm{N}$ application and subsequent reduction found in this study is in line with observations by Dilly $(2001,2003)$. However, the studies by Dilly applied C substrates to relate the observed RQ to the substrate utilization dynamics. Other research has indicated that $\mathrm{N}$ applications increase the easily metabolizable $\mathrm{C}$ in grassland soil (Loiseau and Soussana, 1999) and stimulate $C$ transformations within $24 \mathrm{~h}$ after $\mathrm{N}$ application but not in the long-term (Smith et al., 1989). Therefore a short-term increase in metabolizable C substrate followed by its subsequent consumption may have been responsible for the observed $\mathrm{RQ}_{\text {som }}$ dynamics. This agrees with studies that have found lower RQ values when more reduced organic substrates were metabolized (Klein, 1977). The different RQ dynamics are also reflected in the different RQ-nitrification rate relationships depending on the time after $\mathrm{N}$ application (Fig. 5). The differences in the observed dynamics may reflect the influence of different mineral $\mathrm{N}$ concentrations on nitrifier dynamics in soil. In particular, shortly after $\mathrm{NH}_{4}^{+}$supply, the $\mathrm{NH}_{4}^{+}$oxidizers may be more active and show different dynamics than during other times (Fig. 5).

\section{Denitrification Rate Calculated by the Barometric Process Separation Technique}

At $22.5 \mathrm{~h}$ after $\mathrm{N}$ application the headspace of the BaPS unit contained $6.7 \mu \mathrm{L} \mathrm{L}^{-1} \mathrm{~N}_{2}$ derived from the labeled pool and $9.5 \mu \mathrm{L} \mathrm{L}^{-1} \mathrm{~N}_{2} \mathrm{O}\left(\mathrm{N}_{2} \mathrm{O} / \mathrm{N}_{2}=1.4\right)$. At $69.9 \mathrm{~h}$ after $\mathrm{N}$ application, the headspace contained $2.9 \mu \mathrm{L} \mathrm{L}^{-1} \mathrm{~N}_{2}$ and $3.0 \mu \mathrm{L} \mathrm{L}^{-1} \mathrm{~N}_{2} \mathrm{O}\left(\mathrm{N}_{2} \mathrm{O} / \mathrm{N}_{2}=1.0\right)$. On both occasions the $\mathrm{N}_{2} \mathrm{O}$ was enriched to 35.9 and 24.6 atm $\%{ }^{15} \mathrm{~N}$, respectively. Therefore, denitrification was occurring during BaPS incubations. However, the BaPS output showed, in all cases, a negative (set to zero) denitrification rate. Obviously, the calculation procedure for denitrification which is performed via the $\mathrm{CO}_{2}-\mathrm{O}_{2}$ gas balance in the system (Ingwersen et al., 1999) produced erroneous results. However, this problem is only of minor importance compared with the large influence of differing RQ values on the nitrification rate calculation.

\section{Using the Barometric Process Separation Method to Determine Gross Nitrification Rates}

Our study showed that the BaPS method without the adjustment of the parameters that are needed for the calculations, in particular the RQ value, does not accurately calculate the gross nitrification rates. To obtain accurate nitrification rates we recommend cross-calibrating the BaPS with the ${ }^{15} \mathrm{~N}$ technique for every soil. Since the RQ values change with time after $\mathrm{N}$ application (Table 1) the cross-comparison should be performed over the anticipated range of mineral $\mathrm{N}$ concentrations. Furthermore, substrate characteristics change over time (Klein, 1977) and therefore, it would be ideal to carry out the cross-calibration during all seasons per year. To further increase the accuracy of the BaPS calculations, a cross calibration with a double labeling approach $\left({ }^{15} \mathrm{NH}_{4}^{+}\right.$and $\left.{ }^{15} \mathrm{NO}_{3}^{-}\right)$is recommended because this also allows the determination of the aut/(aut + het $)$ ratio (Müller et al., 2004). However, variation in this ratio has only a minor influence on the determination of the gross nitrification rates by BaPS compared with the variation in the RQ value (Breuer et al., 2002; Ingwersen et al., 1999).

\section{Method to Determine Respiratory Quotient of Utilized Soil Organic Matter}

Application of the BaPS- $-{ }^{15} \mathrm{~N}$ technique determines $\mathrm{RQ}_{\mathrm{SOM}}$ values that are closely associated with the SOM turnover in soil because processes such as nitrification and denitrification, which influence the RQ value, are taken into account. Earlier studies were not able to estimate the $\mathrm{O}_{2}$ uptake derived from nitrification and reported only $\mathrm{RQ}_{\text {net }}$ values that may have little to do with the actual substrate utilization dynamics as mentioned by Dilly (2003). The $\mathrm{RQ}_{\text {som }}$ value is associated with the oxidation state of the substrate and therefore provides an indication of how easy it can be metabolized (i.e., decreasing $\mathrm{RQ}_{\mathrm{som}}$ values indicate that the substrate is more difficult to metabolize). Therefore, the $\mathrm{RQ}_{\text {som }}$ value for SOM turnover can serve as an indicator for SOM quality status in soil. In general, the SOM quality is assessed by the abundance of certain SOM fractions (Feng, 2002). However, the $\mathrm{RQ}_{\text {som }}$ value reported here may serve as a single index parameter of the overall SOM quality status of a system. It can easily be determined via BaPS- ${ }^{15} \mathrm{~N}$, be assessed under various $\mathrm{N}$ application and management practices, and measured during the full range of field conditions throughout the year. Such an index may serve as a quality-indicator in SOMturnover models, which are based on the quality-theory (Q-theory) (Ågren and Bosatta, 1996; Bosatta and Ågren, 1991; Hyvönen and Ågren, 2001).

\section{CONCLUSIONS}

The combination of the BaPS and ${ }^{15} \mathrm{~N}$ technique to determine gross nitrification rates allowed us to derive respiratory quotients of SOM turnover $\left(\mathrm{RQ}_{\mathrm{SOM}}\right)$ for an old grassland soil. Processes such as nitrification and denitrification may have a substantial impact on the observed net $\mathrm{RQ}$ value. The $\mathrm{RQ}_{\text {som }}$ value derived with the BaPS $-{ }^{15} \mathrm{~N}$ method is much more closely related to the actual SOM turnover. The resulting $\mathrm{RQ}_{\text {som }}$ value may serve as a single indicator of the overall SOM quality status of an ecosystem. If the correct parameters 
for the BaPS calculations, such as the RQ value, are determined, (e.g., via cross-calibration with the ${ }^{15} \mathrm{~N}$ dilution technique), the BaPS method provides a quick and easy-to-apply technique to assess gross nitrification and soil respiration rates in ecosystems studies where no additional $\mathrm{N}$ input is desired.

\section{ACKNOWLEDGMENTS}

We thank the UMS GmbH München for providing us with a specially designed measuring unit that enabled us to carry out the BaPS $-{ }^{15} \mathrm{~N}$ measurements. Thanks to Roger Cresswell for the ${ }^{15} \mathrm{~N}$ analysis. We are grateful to Oliver Dilly for his detailed comments on an early draft of this manuscript.

\section{REFERENCES}

Ågren, G.I., and E. Bosatta. 1996. Quality: A bridge between theory and experiment in soil organic matter studies. Oikos 76:522-528.

Andersen, C.P., and C.F. Scagel. 1997. Nutrient availability alters belowground respiration of ozone-exposed ponderosa pine. Tree Phys. 17:377-387.

Bosatta, E., and G.I. Ågren. 1991. Dynamics of carbon and nitrogen in the organic matter of the soil: A generic theory. Am. Nat. 138: 227-245.

Breuer, L., R. Kiese, and K. Butterbach-Bahl. 2002. Temperature and moisture effects on nitrification rates in tropical rain-forest soils. Soil Sci. Soc. Am. J. 66:834-844.

Dilly, O. 2001. Microbial respiratory quotient during basal metabolism and after glucose amendment in soils and litter. Soil Biol. Biochem. 33:117-127.

Dilly, O. 2003. Regulation of the respiratory quotient of soil microbiota by availability of nutrients. FEMS Microbiol. Ecol. 43:375-381.

Feng, X. 2002. A theoretical analysis of carbon isotope evolution of decomposing plant litters and soil organic matter. Glob. Biogeochem. Cycles 16:66/1-66/11.

Hyvönen, R., and G.I. Ågren. 2001. Decomposer invasion rate, decomposer growth rate, and substrate chemical quality: How they influence soil organic matter turnover. Can. J. For. Res. 31:1594-1601.

Ingwersen, J., K. Butterbach-Bahl, R. Gasche, O. Richter, and H. Papen. 1999. Barometric process separation: New method to quantify nitrification, denitrification, and nitrous dioxide sources in soils. Soil Sci. Soc. Am. J. 63:117-128.

Jäger, H.-J., S.W. Schmidt, C. Kammann, L. Grünhage, C. Müller, and
K. Hanewald. 2003. The University of Giessen Free-Air Carbon Dioxide Enrichment Study: Description of the experimental site and of a new enrichment system. J. Appl. Bot. 77:117-127.

Kirkham, D., and W.V. Bartholomew. 1954. Equations for following nutrient transformations in soil, utilizing tracer data. Soil Sci. Soc. Am. Proc. 18:33-34.

Klein, D.A. 1977. Seasonal carbon flow and decomposer parameter relationships in a semiarid grassland soil. Ecology 58:184-190.

Loiseau, P., and J.F. Soussana. 1999. Elevated $\left[\mathrm{CO}_{2}\right]$, temperature increase and $\mathrm{N}$ supply effects on the accumulation of below-ground carbon in a temperate grassland ecosystem. Plant Soil 212:123-134.

Müller, C., R.J. Stevens, and R.J. Laughlin. 2004. A ${ }^{15}$ N tracing model to analyse $\mathrm{N}$ transformations in old grassland soil. Soil Biol. Biochem. 36:619-632.

Scagel, C.F., and C.P. Andersen. 1997. Seasonal changes in root and soil respiration of ozone-exposed ponderosa pine (Pinus ponderosa) grown in different substrates. New Phytol. 136:627-643.

Schlichting, E., H.P. Blume, and K. Stahr. 1995. Bodenkundliches Praktikum Blackwell, Berlin-Wien.

Smith, M.S., C.W. Rice, and E.A. Paul. 1989. Metabolism of labeled organic nitrogen in soil: Regulation by inorganic nitrogen. Soil Sci. Soc. Am. J. 53:768-773.

Stark, J.M. 2000. Nutrient transformations. p. 215-234. In O.E. Sala et al. (ed.) Methods in ecosystem science. Springer, New York.

Stevens, R.J., and R.J. Laughlin. 1994. Determining nitrogen-15 in nitrite or nitrate by producing nitrous oxide. Soil Sci. Soc. Am. J. 58:1108-1116.

Stevens, R.J., and R.J. Laughlin. 1995. Nitrite transformations during soil extraction with potassium chloride. Soil Sci. Soc. Am. J. 59:933938.

Stevens, R.J., and R.J. Laughlin. 1998. Measurement of nitrous oxide and di-nitrogen emissions from agricultural soils. Nutr. Cycling Agroecosyst. 52:131-139.

Stevens, R.J., R.J. Laughlin, G.J. Atkins, and S.J. Prosser. 1993. Automated determination of nitrogen-15 labeled dinitrogen and nitrous oxide by mass spectrometry. Soil Sci. Soc. Am. J. 57:981-988.

Stockdale, E.A., D.J. Hatch, D.V. Murphy, S.F. Ledgard, and C.J. Watson. 2002. Verifying the nitrification to immobilisation ratio $(N / I)$ as a key determinant of potential nitrate loss in grassland and arable soils. Agronomy 22:831-838.

UMS. 2003. BaPS Barometric Process Separation-system for the determination of microbial nitrogen and carbon conversion rates in soils. 3rd ed. (Available online at http://www.ums-muc.de/pdf/bede/BaPSUserManual.pdf.) UMS GmbH, Munich.

Watson, C.J., and C.L. Mills. 1998. Gross nitrogen transformations in grassland soils as affected by previous management intensity. Soil Biol. Biochem. 30:743-753. 